\title{
Bauschinger Effect and Back Stress in a Dual Phase Steel
}

\author{
M.T. MA, ${ }^{1)}$ the late B.Z. SUN') and Y. TOMOTA3) \\ 1) Heavy Vehicle Research Institute, Chongqing, China. 2) Central iron and Steel Research Institute Beijing, China. \\ Engineering, Ibaraki University, Nakanarusawa-machi, Hitachi, Ibaraki-ken, 316 Japan. \\ 3) Faculty of
}

(Received on February 10, 1988; accepted in the final form on September 9, 1988)

\begin{abstract}
To clarify the Bauschinger effect behavior in a dual phase steel and the influence of strain aging on it, tension-compression tests were carried out using a Mn-V low alloy steel. This steel shows extremely large transient softening and considerable amount of permanent softening. The strain aging at $448 \mathrm{~K}$ has been found to diminish the transient softening but to remain the permanent softening. The anisotropy in magnetic coercivity in plastically deformed specimens was measured and has been considered to be related with the long range internal stress (back stress). The relationship between the back stress and the magnitude of the permanent softening is discussed.
\end{abstract}

KEY WORDS: Bauschinger effect; dual phase steel; back stress; strain-aging; coercivity

\section{Introduction}

Low carbon or HSLA steels which were intercritically annealed or control-rolled to produce a mixture of martensite and ferrite were called dual phase steel. ${ }^{1)}$ The dual phase steel has been known to exhibit remarkable Bauschinger effect: the work-hardening depends on the deformation history. ${ }^{2-5}$ A main origin of the Bauschinger effect is estimated to be the back stress, i.e., long range internal stress ${ }^{(6)}$ which has a crucial influence on the properties of the dual phase steel. The aims of this paper are, then, to show the role of the back stress on the Bauschinger effect in a $\mathrm{Mn}-\mathrm{V}$ dual phase steel and consequently to clarify the influence of the strain aging on the forward and reverse flow curves. The back stress is discussed both from the difference between forward and backward flow curves of pre-deformed specimens and from the measurement of the anisotropy in the coercivity of the plastically deformed specimens.

\section{Experimental Procedure}

The steel used in this experiment is $10 \mathrm{MnV}$ whose chemical compositions are $0.13 \mathrm{C}, 0.28 \mathrm{Si}, 1.31 \mathrm{Mn}$, $0.005 \mathrm{P}, 0.009 \mathrm{~S}$, and $0.04 \mathrm{~V}$ in $w \mathrm{t} \%$. After normalizing at $1203 \mathrm{~K}$ for $3.6 \mathrm{ks}$, the blanks were machined to tension-compression test specimens with $6 \mathrm{~mm}$ in diameter and $12 \mathrm{~mm}$ in gage length. The specimens were heated up to $1003 \mathrm{~K}$, held for $1.2 \mathrm{ks}$ in nitrogen gas atmosphere and then quenched into water. The tension-compression tests were carried out on an MTS 810 machine at a cross head speed of $1 \mathrm{~mm} / \mathrm{min}(0.017 \mathrm{~mm} / \mathrm{s})$. Some specimens were aged at $448 \mathrm{~K}$ for $7.2 \mathrm{ks}$ after pre-tension and then tested in tension or compression. The size and volume fraction of martensite colony were measured by linear analysis and point counting method on optical micrographs. The specimens which were subjected by various strains and strain histories were sectioned to $12 \mathrm{~mm}$ long cylindrical samples, and the coercivities of the longitudinal and transverse directions of the samples were measured. The detail of this measuring method was already reported elsewhere. ${ }^{1)}$

\section{Experimental Results}

\subsection{Microstructure}

The typical microstructure of the specimen is shown in Fig. 1 where two kinds of martensite morphology, i.e., large martensite nodules with about $13 \mu \mathrm{m}$ in diameter and tiny martensite islands with the average diameter of $1.5 \mu \mathrm{m}$ along ferrite grain boundaries, can be observed. The volume fraction of the former type of martensite is $20 \%$ and that of the latter one is about $5 \%$ (then $25 \%$ in total).

\subsection{The Features of the Bauschinger Effect of the Inter- critically Annealed Steel}

The examples of tension-compression flow curves are shown in Fig. 2. As is well known, the continuous yielding can be observed and the work-hardening is

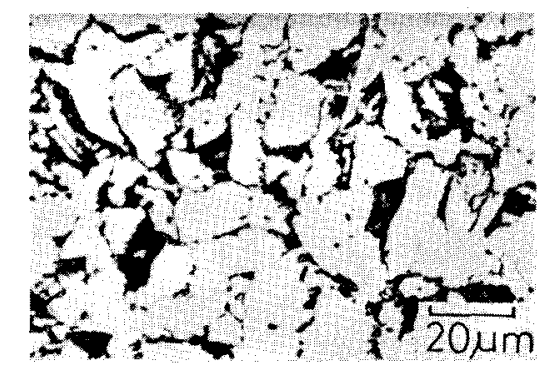

Fig. 1. Optical micrograph of the specimen. 


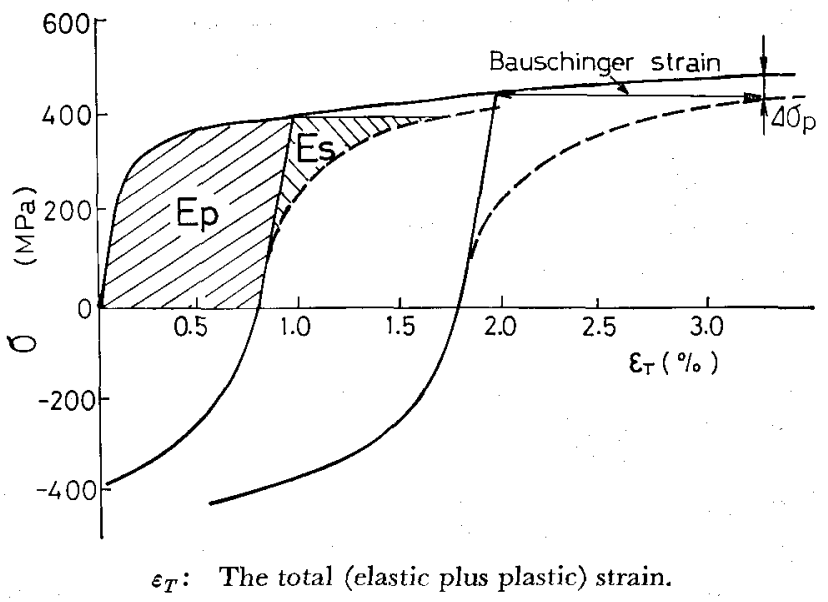

Fig. 2. The influence of pre-strain on the Bauschinger effect.

very high in the beginning of deformation. The compression flow curves were redrawn in the tension side by using cumulative plastic strain. By comparing these curves, a large transient softening and some permanent one can be found. Some workers have reported a considerable amount of the permanent softening in dual phase steels, ${ }^{3}$ but others have not observed. ${ }^{4,6)}$ This discrepancy seems to stem from the differences in volume fraction, strength, and topology of the harder phase colony. In a case that the martensite is not plastically deformed during the tension-compression test, a clear permanent softening would appear, while little permanent softening could be expected in a case that both component phases deform plastically (see Fig. 7 of Ref. 6)). The present specimen in which the small volume fraction of isolated islands of strong martensite is scattered in the matrix, must belong to the former case. On the other hand, the large transient softening has been commonly observed by above workers. ${ }^{3-6)}$ Because of this distinguished rounding of the backward flow curve, Uko $e l a l$. have reported that it is not easy to determine the amount of permanent softening in dual phase steels compared with steels containing cementite particles. ${ }^{3)}$ Then, in this study, the amount of permanent softening $\left(\Delta \sigma_{p}\right)$ was determined at the Bauschinger strain $^{5}$ by comparing two relevant curves, i.e., tension and redrawn compression (dashed line) curves, as shown in Fig. 2. As other Bauschinger parameters, the Bauschinger stress (B.S. $=\sigma_{P}^{*}$ (prestress $)-\left|\sigma_{R}^{*}\right|(0.1 \%$ compressive proof stress $\left.)\right)$ and the energy parameter of Bauschinger effect (BEEP) ${ }^{5}$ which is defined as $E_{s} / E_{p}$ (see Fig. 2) were mcasured. These Bauschinger parameters were plotted as a function of pre-strain in Fig. 3. The B.S. and $\Delta \sigma_{p}$ are found to increase rapidly in the beginning and then to show a trend of saturation. On the contrary, the BEEP decreases drastically with an increase in prestrain.

\subsection{Effect of Strain Aging on the Bauschinger Effect}

The influence of strain aging on the Bauschinger effect is shown in Fig. 4. The curve (1) shows an initial tension flow curve. The curves (2) and (3) are

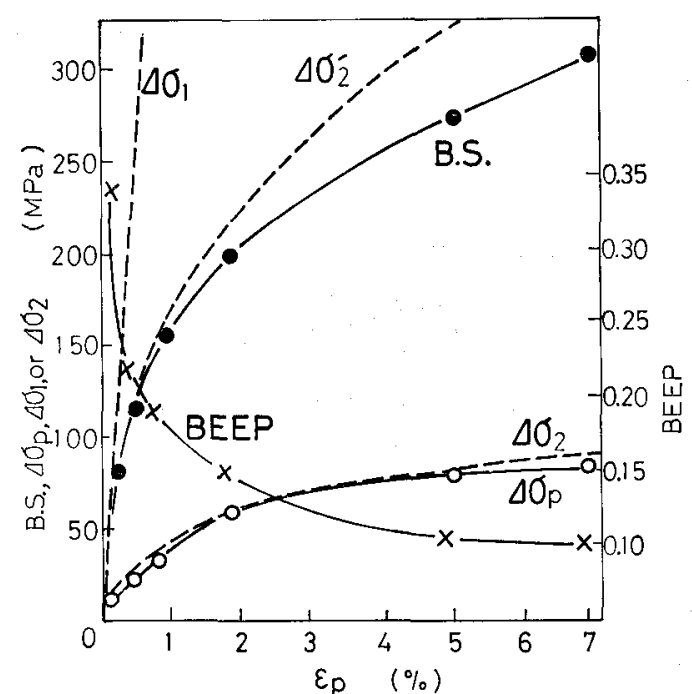

-..-: $\Delta \sigma_{1}$ and $\Delta \sigma_{2}$ calculated from Eqs. (4) and (7), respectively.

See the text for the detailed explanation.

Fig. 3. The Bauschinger parameters, B.S., $\Delta \sigma_{p}$, and BEEP as a function of pre-strain.

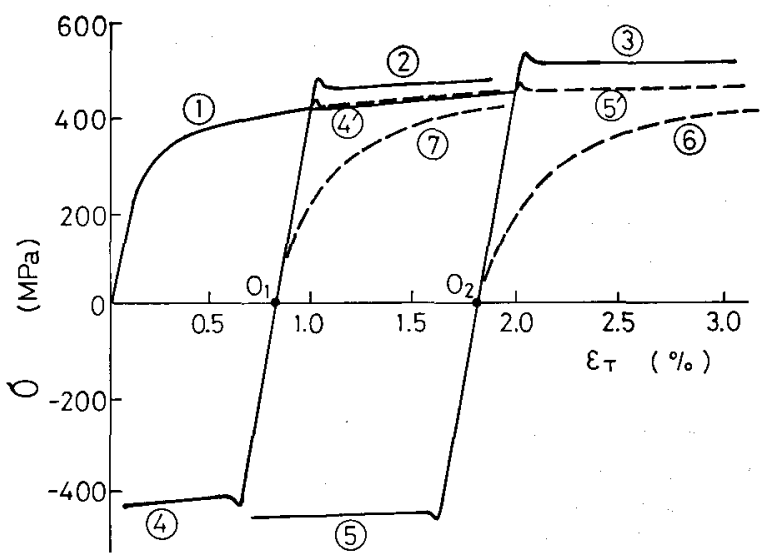

Fig. 4. Influence of strain aging at $448 \mathrm{~K}$ on the Bauschinger effect. The dashed curves for non-aged specimens were redrawn from Fig. 2.

tension ones after aging at $\mathrm{O}_{1}$ and $\mathrm{O}_{2}$, respectively, while (4) and (5) are compressive ones after the aging. The dashed curves (4)' and (5)' were redrawn (4) and (5) as a function of cumulative plastic strain. The curves (6) and (7) were taken from Fig. 2 for reference (non-aged case). The usual strain aging can be seen from curves (2) and (3). Very interesting is, for example, a comparison of curves (2) and (4)'. Both curves show the discontinuous yielding and become almost parallel, whose difference is nearly identical with the $\Delta \sigma_{p}$ of non-aged case (see Fig. 2). It means that the transient softening (rounding of the compressive flow curve in the beginning of deformation) disappears but the permanent softening still remains even after the aging. The similar results have been reported by Kumakura ${ }^{8)}$ in annealed carbon steels.

\subsection{The Anisotropy in the Coercivity of Plastically De- formed Specimens}

The anisotropy in the coercivity of a plastically deformed dual phase steel was found by one of the pres- 
Table 1. The coercivity of the specimen in various conditions.

\begin{tabular}{lcc}
\hline \multicolumn{1}{c}{ Conditions of the specimen } & $\begin{array}{c}H_{c}^{a} \\
(\mathrm{~A} / \mathrm{m})\end{array}$ & $\begin{array}{c}H_{c}^{r} \\
(\mathrm{~A} / \mathrm{m})\end{array}$ \\
\hline As heat-treated & 420 & 400 \\
Deformed in tension $(2 \%)$ & 660 & 400 \\
$\begin{array}{l}\text { Deformed in tension }(2 \%) \text { and aged } \\
\text { Deformed in compression }(0.56 \%)\end{array}$ & 660 & 410 \\
$\quad \begin{array}{l}\text { after tension }(2 \%) \\
\begin{array}{l}\text { Deformed in compression }(1.09 \%) \\
\text { after tension }(2 \%)\end{array}\end{array}$ & 535 & 410 \\
\hline
\end{tabular}

$H_{c}^{a}:$ Longitudinal (axial) direction

$H_{c}^{r}$ : Transverse (radius) one

ent authors (Ma) and Chen.9) According to their finding, this anisotropy is increased with plastic strain and also changes with strain reversal, and to be considered to reflect the amount of internal stress. Then, the coercivity of some specimens were measured and the results are presented in Table 1 .

A considerable difference is found between the coercivity of longitudinal direction and that of transverse one in a $2 \%$ strained specimen while little difference is observed in a non-deformed specimen. When a specimen was compressed after tension, the anisotropy was decreased with increasing the compressive strain and disappeared at around 1\% compression. According to the previous work done by $\mathrm{Ma}$ and Sun, ${ }^{10}$ the anisotropy developed by prior plastic deformation was decreased, then cancelled, and again developed with an increase in the reverse plastic flow. The data of the strain-aged specimen are almost identical with those in non-aged one (both deformed $2 \%$ in tension). This is consistent with the trend of the permanent softening in aged and non-aged specimens in Fig. 4.

\section{Discussion}

Since the martensite colony seemed to be almost plastically non-deformable within the strain range examined in this study, the Bauschinger behavior of the present steel must resemble that of a dispersionhardened alloy. As is already done by other workers, ${ }^{3,5)}$ the flow stress after the prestrain $\left(\varepsilon_{p}^{*}\right)$ in the forward direction $\left(\sigma_{F}\right)$ can be normally expressed as

$$
\sigma_{F}=\sigma_{0}+\sigma_{f}+\sigma_{b}
$$

and that in the backward direction $\left(\sigma_{R}\right)$ is,

$$
\sigma_{R}=\sigma_{0}+\sigma_{f}^{\prime}-\sigma_{b}^{\prime}
$$

where, $\sigma_{0}$ : the initial yield strength

$\sigma_{f}, \sigma_{f}^{\prime}:$ the forest hardening

$\sigma_{b}, \sigma_{b}^{\prime}$ : the back stress (long range internal stress)*.

These stresses except $\sigma_{0}$ should be expressed by different functions of the strain after $\varepsilon_{p}^{*}$, respectively.
Therefore, it is not easy to determine the exact value of $\sigma_{b}$ from the flow curves. If the changes in $\sigma_{f}$ and $\sigma_{f}^{\prime}$ and those in $\sigma_{b}$ and $\sigma_{b}^{\prime}$ could be expressed by identical equations of the strain after the pre-strain $\varepsilon_{p}^{*}$, it must be possible to calculate $\sigma_{b}$ from the tension and compression flow curves by using Eqs. (1) and (2). In some composite materials, ${ }^{11)}$ dispersion hardened alloys, ${ }^{12,13)}$ and so on, the $\sigma_{b}$ seems to be successfully predicted by comparing the two flow curves. In single phase alloys, however, the physical meaning of the back stress is not clear and difficult to obtain by above method. Kishi et al. have proposed that the mean back stress can be measured by means of AE technique. ${ }^{14)}$

Although the work hardening in this dual phase steel is similar to that in a dispersion-hardened alloy, it is not easy to estimate the $\sigma_{b}$ by mechanical tests. Because of its coarse microstructure, the plastic flow in the softer phase (ferrite) is not so different from that in a single phase alloy and the fluctuation of the back stress must not be ignored especially for the reversed deformation. According to the continuum model, ${ }^{15}$ ) the 2nd stage of deformation in a two-ductile-phase alloy where only the soft phase deforms plastically, is given by

$$
\sigma_{38}^{A}\left\langle\varepsilon_{p}\right\rangle=\sigma_{\text {flow }}^{I}\left\langle\varepsilon_{p}^{I}\right\rangle+f A \varepsilon_{p}^{I}
$$

when the applied stress $\left(\sigma_{33}^{A}\right)$ is loaded along the $x_{8}$ axis. A symbol $<>$ means a function of the variant in the bracket. Here, $\sigma_{\text {flow }}^{I}\left\langle\varepsilon_{p}^{I}\right\rangle$ means the flow curve of the softer phase, $\varepsilon_{p}^{I}$ the average plastic strain of the softer phase (the plastic strain in a whole specimen is $\left.\varepsilon_{p}=(1-f) \varepsilon_{p}^{I}\right)$, and $f$ the volume fraction of the harder phase. The constant $A$ is equal to $E(7-5 \nu) / 10\left(1-\nu^{2}\right)$ in a case of spherical second phase particle, where $E$ and $\nu$ refer to Young's modulus and Poisson's ratio, respectively. The second term of Eq. (3) is corresponding to the back stress $\sigma_{b}$ in Eq. (1). From this, the difference between $\sigma_{F}$ and $\sigma_{R}$ after the pre-strain $\varepsilon_{p}^{*}$ is given by

$$
\Delta \sigma_{1}=\frac{2 f}{1-f} A \varepsilon_{p}^{*}
$$

Putting $f=0.25, \nu=0.3$, and $E=206 \mathrm{GPa}$ into the equation, the $\Delta \sigma_{1} v s . \varepsilon_{p}^{*}$ relation was obtained as presented in Fig. 2. The calculated $\Delta \sigma_{1}$ is found much larger than B.S. and $\Delta \sigma_{p}$ measured.

As frequently discussed, the plastic relaxation would occur easily in an alloy with large harder particles so that the average long range internal stress would be decreased. By this plastic relaxation, Eq. (3) may be changed to a form of

$$
\begin{aligned}
\sigma_{33}^{A}\left\langle\varepsilon_{p}\right\rangle= & \sigma_{\text {flow }}^{I}\left\langle\frac{\varepsilon_{p}}{1-f}\right\rangle+\Delta \sigma_{f}\left\langle\frac{\varepsilon_{p}}{1-f}-\varepsilon_{p, \text { eff }}\right\rangle \\
& +f A \varepsilon_{p, \text { eff }} \quad \ldots \ldots \ldots \ldots \ldots \ldots \ldots \ldots \ldots \ldots \ldots \ldots \ldots \ldots \ldots \ldots \ldots \ldots \ldots \ldots \ldots \ldots
\end{aligned}
$$

where, $\varepsilon_{p \text {, eff }}: \quad$ unrelaxed misfit strain.

\footnotetext{
* In a case of shear deformation $\gamma_{p}$, the work hardening can be directly connected with the long range internal stress $\tau_{\mathrm{int}}$, namely, the back stress $\tau_{b}=\tau_{\text {int }}$. But, in a case of tensile deformation, the average misfit strains are $-2 \varepsilon_{11}=-2 \varepsilon_{22}=\varepsilon_{33}=\varepsilon_{p}$, and the average internal stresses are expressed as $-2 \sigma_{11}=-2 \sigma_{22}=\sigma_{33}=\sigma_{\text {int }}$. Thus, the back stress $\sigma_{b}$ in Eqs. (1) and (2), i.e., the amount of work hardening is shown by $3 / 2 \sigma_{\text {int }}$.
} 
The third term in Eq. (5) is associated with $\sigma_{b}$ in Eq. (1) while the second term is the additional forest hardening due to geometrically necessary dislocations (the increment of dislocations by plastic relaxation). A quite similar equation has been proposed by Brown and Stobbs for a dispersion-hardened alloy. ${ }^{13)}$ They have given $\varepsilon_{p \text {, eff }}$ as a form of

$$
\varepsilon_{p, \mathrm{eff}}=K\left(\varepsilon_{p} \cdot b / r\right)^{1 / 2}
$$

where, $b$ : Burgers vector

$r$ : average diameter of particles

$K$ : constant (when $f$ is very small, $\varepsilon_{p}^{t} \simeq \varepsilon_{p}$ ). Uko et al. applied Eq. (6) to steels containing cementite and dual phase HSLA steels. Assuming that the first and second terms of Eq. (5) did not alter by strain path, one could obtain the twice of the third term as the permanent softening.

$$
\Delta \sigma_{2}=\frac{E(7-5 \nu)}{5\left(1-\frac{\nu}{\nu^{2}}\right)} \cdot \frac{f}{\varepsilon_{p, \mathrm{eff}}}
$$

In order to apply Eq. (7) to the present case, the superposition of two kinds of martensite colony (diameters of 13 and $1.5 \mu \mathrm{m}$ ) is necessary. The value of $K$ is taken as 0.7 according to Uko et al ${ }^{3}{ }^{3}$ As result, the agreement between the calculation and experimental result on the permanent softening is revealed to be very good as shown in Fig. 3. In this calculation, the effective misfit strain $\varepsilon_{j \text {, efr }}$ becomes approximately 0.001 around $\varepsilon_{p}^{*}=0.01 \sim 0.05$. This is, however, smaller than the predictions by Araki et al. ${ }^{16)}$ and FEM calculations ${ }^{17)}$ in which $\varepsilon_{p}$, wf has been estimated as about 0.004 . Then, if one uses the $\varepsilon_{p}$,erf of the order of 0.001 , one might obtain a good agreement between $\Delta \sigma_{2}$ and $\Delta \sigma_{p}$, but could not explain the other properties such as flow stress. On the other hand, if one put 2.8 into $K$ of Eq. (6) (that is, $\varepsilon_{p \text {,eff }}$ is assumed around 0.004$), \Delta \sigma_{2}$ would become near the measured B.S. (see $\Delta \sigma_{2}^{\prime}$ in Fig. 3 ).

Therefore, in order to predict the exact in situ back stress from Bauschinger test, the theoretical background is not enough. The present study, however, strongly suggests that the back stress plays an important role in the work-hardening and Bauschinger effect in a dual phase steel. The misfit strain, i.e., the back stress can not be relaxed by the aging and may be possibly related with the anisotropic coercivity.

\section{Conclusions}

(1) A large transient softening and a considerable amount of permanent softening have been observed in the present dual phase steel in which the small amount of strong martensite islands and somewhat large martensite colonies are dispersed in the soft ferrite matrix.

(2) The strain aging at $448 \mathrm{~K}$ has been found to eliminate the rounding in the beginning of the reverse flow curve, that is, to diminish the transient softening. The magnitude of the permanent softening is, however, not influenced by the aging.

(3) The anisotropy in coercivity has been found in deformed specimens. The degree of the anisotropy is changed according to tension and compression deformation and seems to reflect the magnitude of the back stress. The strain aging does not influence this anisotropic coercivity.

(4) The Bauschinger behavior of the present steel is concluded to be similar to that in dispersion-hardened alloys. Some different points come from the coarse martensite colonies of this stecl. The back stress must play a dominant role in the Bauschinger behavior and its magnitude may be predicted from the magnetic coercivity measurement.

\section{Acknowledgements}

The most part of this paper was made during the seminar on "micromechanics of two-phase materials" at Heavy Vehicle Research Institute in Chongqing (June, 1987). One of the authors (Tomota) would like to appreciate China Automobile Co. for their invitation as a lecturer at the seminar. The authors wish to thank Mr. Guo for his helpful discussion, who had stayed at Ibaraki University as a visiting scholar for two years (1982-1984) and now at China Heavy Vehicle Automobile Co. in Chongqing.

\section{REFERENCES}

1) for example, Fundamentals of Dual Phase Steels, ed. by R. A. Kol and B. L. Bramfitt, TMS-AIME, New York, (1981).

2) J. Gerbase, J. D. Embury and R. M. Hobbs: Structure and Properties of Dual Phase Steels, ed. by R. A. Kot and J. W. Morris, Jr., TMS-AIME, New York, (1979), 128.

3) D. Uko, R. Sower and J. D. Embury: Met. Technol., 7 (1980), 359.

4) D. Tseng and F. H. Vitovec: Fundamentals of Dual Phase Steels, ed. by R. A. Kot and B. L. Bramfitt, TMS-AIME, New York, (1981), 128.

5) A. Gocl, R. K. Ray and G.S. Murty: Scr. metall., 17 (1983), 375.

6) Y. Tomota: Mater. Sci. Technol., 3 (1987), 415.

7) D. X. Chen and M. T. Ma: Central Iron Steel Res. Inst. Bull. (China), 4 (1984), 341.

8) for example, S. Kumakura: J. Jpn. Soc. Mech. Eng., 70 (1967), 1287.

9) M. T. Ma and D. X. Chen: Chinese Phys. Lett., 1 (1984), 35.

10) M. T. Ma and Z. B. Sun: Proc. of Int. Conf. on Computational Mechanics '86, IV, Tokyo Springer-Verlag, Tokyo, (1986), 83.

11) for example, O. Yanagisawa and T. Yano: Bull. Jpn. Inst. Met., 26 (1987), 862.

12) for example, N. Matsuda and K. Matsuura: J. Jpn. Inst. Met., 48 (1984), 362.

13) L. M. Brown and W. M. Stobbs: Philo. Mag., 27 (1971), $1185 \& 1205$.

14) T. Kishi, Y. Sakakibara, Y. Obata and R. Horiuchi: $J$. Jpn. Inst. Met., 41 (1977), 890.

15) Y. Tomota, K. Kuroki, T. Mori and I. Tamura: Mater. Sci. Eng., 24 (1976), 85.

16) K. Araki, Y. Takada and K. Nakada: Trans. Iron Steel Inst. Jpn., 17 (1977), 710.

17) Y. Tomota, I. Tanimoto and K. Kuroki: Trans. Jpn. Soc. Mech. Eng., 17A (1982), 528. 